\title{
Correction of Severe Anemia in a Patient with End Stage Renal Disease and Myelodysplastic Syndrome
}

\author{
Ankita Patel, Suchita Mehta*, Ahmad Waseef, Subodh Saggi \\ Department of Nephrology, SUNY Downstate Medical Center, New York, USA \\ Email: ${ }^{*}$ mehtasuchita@gmail.com
}

Received 20 July 2014; revised 18 August 2014; accepted 17 September 2014

Copyright (C) 2014 by authors and Scientific Research Publishing Inc.

This work is licensed under the Creative Commons Attribution International License (CC BY). http://creativecommons.org/licenses/by/4.0/

(c) (i) Open Access

\begin{abstract}
Background: Anemia is a common complication of end-stage renal disease (ESRD) and is effectively managed by Erythropoietin Stimulating Agents (ESAs) and intravenous iron therapy. Management of anemia in ESRD patients with myelodysplastic syndrome (MDS) poses a unique challenge. ESAs even at extremely high doses do not result in a desired response, especially if the patients are iron-overloaded. Case: A 72-year-old man with history of ESRD and MDS on hemodialysis since September 2009 was severely anemic requiring massive doses of ESA in excess of 90,000 units/week. Iron saturation was consistently $>60 \%$; ferritin was $>2500$. Desferrioxamine (DFO) $125 \mathrm{mg} \mathrm{IV} /$ week was begun in November 2010. His PRBC transfusion and ESA requirements declined after the initiation of this therapy. He had 33 ER visits for PRBC transfusions (1 - 3 transfusions/visit) from September 2009 to November 2010 (average: $2.35 /$ month), which decreased to 18 visits in 20 months (average: 0.9/month) after getting DFO. Conclusion: We report a case of MDS with ESRD on hemodialysis where anemia was managed with Desferrioxamine therapy along with ESA, after which it was noted that there was a significant reduction in the number of PRBC transfusions that the patient received along with a decrease in ESA requirements and a decrease in number of hospitalizations, which in the long term could be cost effective.
\end{abstract}

\section{Keywords}

Anemia, Desferrioxamine, ESRD

\section{Background}

Myelodysplastic Syndrome (MDS) comprises a heterogeneous group of malignant stem cell disorders characte-

"Corresponding author.

How to cite this paper: Patel, A., Mehta, S., Waseef, A. and Saggi, S. (2014) Correction of Severe Anemia in a Patient with End Stage Renal Disease and Myelodysplastic Syndrome. Open Journal of Nephrology, 4, 125-129.

http://dx.doi.org/10.4236/ojneph.2014.43018 
rized by dysplastic and ineffective blood cell production from ineffective iron incorporation. Most of these patients require multiple packed red blood cell transfusions. Anemia is a common complication of end-stage renal disease (ESRD) and is effectively managed by Erythropoietin Stimulating Agents (ESAs) and intravenous iron therapy. Management of anemia in ESRD patients with MDS poses a unique challenge. ESAs, even at extremely high doses do not result in a desired response, especially if the patients are iron-overloaded [1]. Patients become dependent on frequent packed red blood cell (PRBC) transfusions, which result in many adverse effects, one of which includes iron overload and its toxicity. We report a case of MDS with ESRD on hemodialysis whose anemia was managed with Desferrioxamine therapy along with EPO, after which it was noted that there was a significant reduction in the dose of ESA as well as the number of PRBC transfusions that the patient received. Further, this patient benefited from a decrease in number of hospitalizations, which in the long term could be cost effective.

\section{Case Presentation}

A 72-year-old African American man with history of Diabetes Mellitus Type II and Hypertension for 15 years was diagnosed with MDS in 2008. He developed End stage renal disease (ESRD) due to Diabetic nephropathy and was started on hemodialysis three times a week in September 2009. He was profoundly anemic requiring massive doses of Erythropoietin (EPO) in excess of 90,000. Despite such high doses of ESA requirement, patient's response was suboptimal and he required multiple hospitalizations for PRBC transfusions, averaging 1 - 2 per week. His iron saturations' were persistently above $60 \%$ and his ferritin's were always greater than 2500 $\mathrm{ng} / \mathrm{ml}$, on occasions even above $10,000 \mathrm{ng} / \mathrm{ml}$, in part related to the excess blood transfusions. In an effort to control his excess iron overload, patient was started on Desferrioxamine (DFO) therapy in November 2010. He was prescribed $125 \mathrm{mg}$ intravenously once a week as a maintenance therapy on an ongoing basis.

After initiation of DFO, his requirements of blood transfusion and multiple hospitalizations were greatly decreased. Overall he had 33 emergency room visits requiring 1 to 3 PRBC transfusions during each visit from September 2009 to November 2010 (an average of 2.35 admissions per month). Remarkably after initiation of DFO he had 18 emergency room visits for transfusions in 20 months (an average of 0.9 admissions per month). Average EPO requirements declined simultaneously over this time period. His hemoglobin, and iron indices are shown in Figure 1.

\section{Discussion}

Anemia is one of the most common presenting features of MDS, apart from disturbances of platelets, white cells and coagulation. Most of the patients with MDS become transfusion dependent. Secondary iron overload from frequent red blood cell transfusions and poor iron incorporation into red blood cells (RBCs) is associated with poor survival in these patients [2]-[4]. Transfusion requirement has been recently recognized as an independent prognostic factor for survival in MDS patients [5]. Benefits of iron chelation therapy have been described in MDS patients who did not have any kidney injury or ESRD [6]-[8]. Such treatments resulted in a reduction of transfusions in such patients in association with a reduction in their iron overload. Iron chelation therapy has also been shown to reduce iron overload in ESRD patients but an effect on their anemia has not been reported before. Here we report a case of a patient who had both ESRD and MDS with profoundly high iron load who benefited from chelation therapy. To our knowledge this is the first case with both ESRD and MDS, where we show his anemia improved and his ESA requirements reduced. We present a hypothesis by which we believe iron chelation might be working under these circumstances where the kidneys and bone marrow are not functioning optimally.

The expression of erythropoietin (EPO) mRNA and protein is regulated primarily at the transcriptional level. Hypoxia is the most physiologically important stimulus for EPO production. It results in the activation of hypoxia inducible factor (HIF), a $\alpha \beta$ heterodimer transcription factor that contains an oxygen-labile $\alpha$ subunit and a constitutively expressed $\beta$ subunit. At normal oxygen tension the $\alpha$-subunit of HIF undergoes post-translational modification by proline hydroxylation and ubiquitylation, causing it to be rapidly degraded. At low oxygen tension, HIF- $1 \alpha$ is not hydroxylated and therefore escapes degradation and it thus translocates into the nucleus, and heterodimerizes with $\beta$ subunit to form the HIF complex [9] [10]. HIF-1 $\alpha$ can be activated in oxygenated cells by inhibitors of prolyl hydroxylase (PH). Desferrioxamine (DFO) has been shown to activate HIF-1 $\alpha$ in vitro, 
with kinetics similar to those associated with hypoxia, and to increase expression of HIF-1 $\alpha$ target genes, including EPO [11]. We believe this happens via inhibition of prolyl hydroxylase by DFO (see Figure 2).
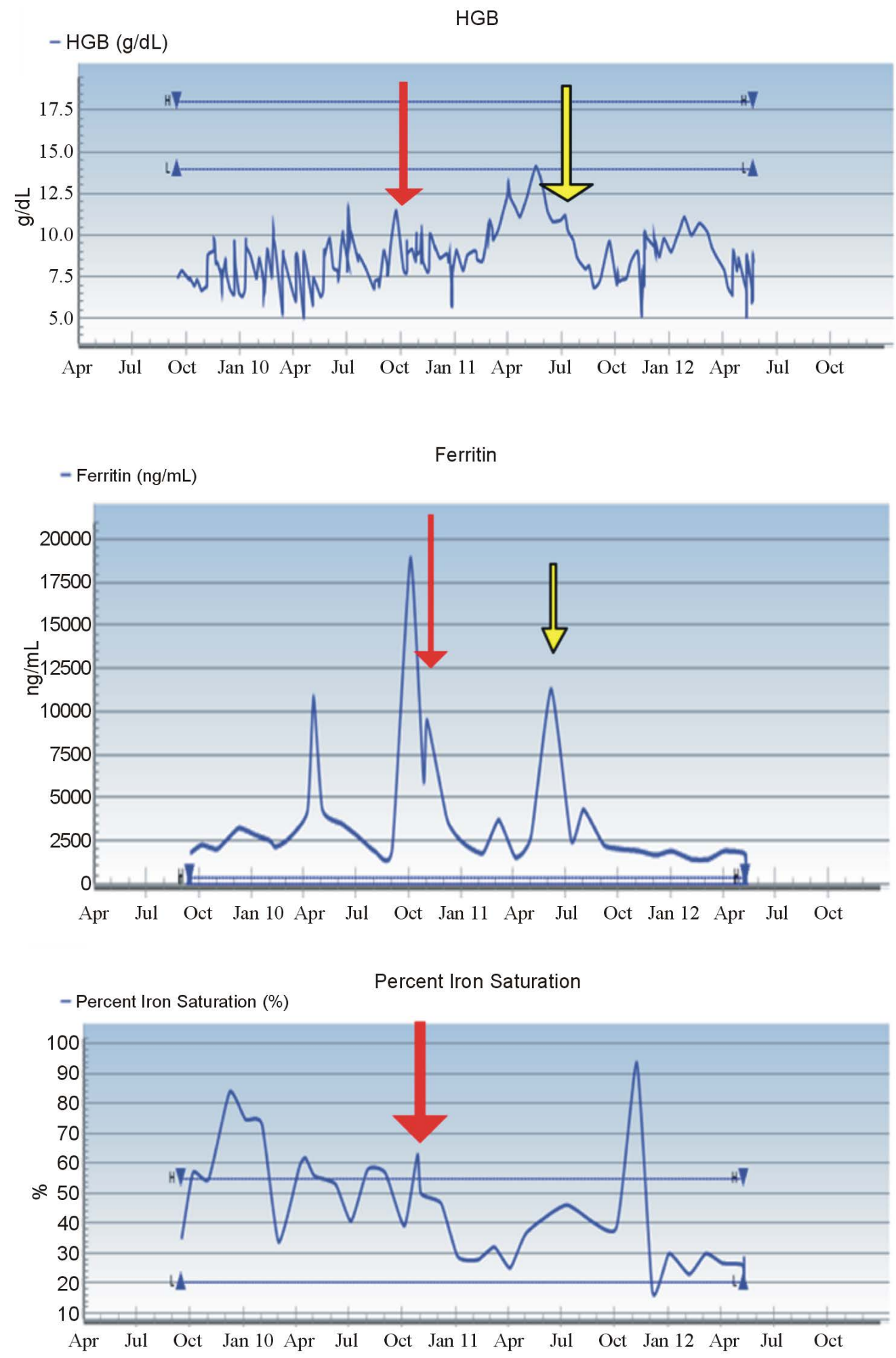

Figure 1. The red arrow represents initiation of DFO therapy. The yellow arrow depicts a rise in ferritin and subsequent decrease in hemoglobin when DFO therapy was held temporarily. 


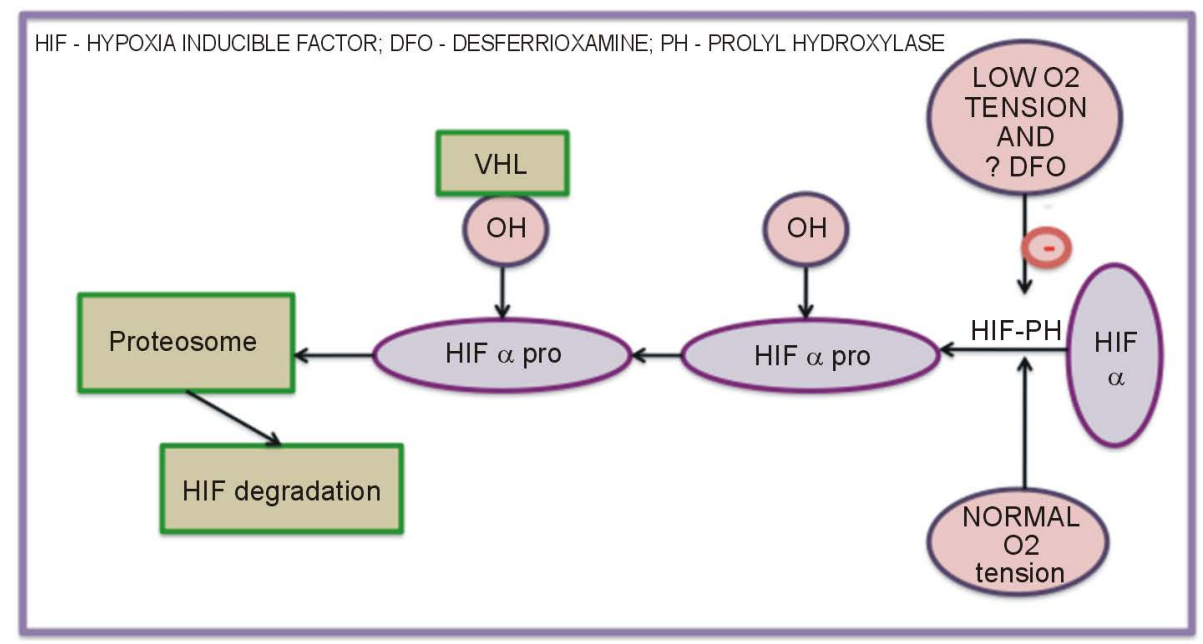

Figure 2. Degradation of hif- $\alpha$ under normal oxygen tension by prolyl hydroxylase. Inhibition of hydroxylation under hypoxic conditions and also possibly by desferrioxamine.

Iron excess is also associated with increased oxidative stress: the accumulation of non-transferrin-bound iron caused by chronic blood transfusions which results in excess extracellular labile plasma iron (LPI) and intracellular labile iron pool (LIP), the principal source of reactive oxygen species (ROS) production. Iron accumulation also causes a decrease of the major cellular antioxidant reduced glutathione (GSH) and increases membrane lipid peroxidation [12] [13]. Furthermore, iron overload itself has an in vitro suppressive effect on erythroid progenitors and seems to increase transfusion requirement. The goal ferritin for patients with chronic kidney disease is now set at 500ug/l, based up on the KDOQI and KDIGO guidelines of anemia management in patients with chronic kidney disease. (http://www.kdigo.org/clinical_practice guidelines/pdf/KDIGO-Anemia GL.pdf; http://www.kidney.org/professionals/KDOQI/guidelines_anemia/ped32.htm)

The mechanisms by which iron chelator therapy may lead to improvement in anemia are unclear. Iron chelators promote iron release from storage sites facilitating its usage by hematopoietic cells. Furthermore, the reduction of iron store seems to up regulate erythropoietin response, resulting in hemoglobin increase [14]. Perhaps, DFO and EPO have a synergistic effect on erythroid precursor cell proliferation [15]. In MDS patients, iron chelation significantly reduces ROS, membrane lipid peroxidation and the LIPs, and concomitantly increases GSH in RBC [16].

Now, with reimbursement rates by Center for Medicare and Medicaid Services (CMS) being dependent on average dose of ESA requirement in a month and also with a possible further cut by $9.4 \%$ in the bundling system for the dialysis centers as proposed by CMS in 2014; cost effective measures to reduce ESA requirements would be beneficial to the patient as well as to a dialysis facility.

(http://www.cms.gov/Outreach-and-Education/Medicare-Learning-Network-MLN/MLNMattersArticles/downlo ads/se0406.pdf;

http://www.renalbusiness.com/news/2013/07/cms-proposes--pay-cut-for-dialysis-providers.aspx)

In our case, once the use of desferrioxamine was initiated there was stabilization of his hemoglobin thus reducing his ESA requirements, reducing his blood transfusions, emergency room visits and hospitalizations.

\section{Conclusion}

Desferrioxamine therapy improves anemia, diminishes blood transfusion and ESA requirements, and reduces emergency room visits and hospitalizations for patients that have both MDS and ESRD. Larger studies would be hard to do as the number of cases with combined co-morbidity of ESRD and MDS are too few. However, if measurements of endogenous and exogenous erythropoietin levels and assessment of intracellular signaling pathways were available, we might better understand the mechanisms of chelation therapy and its role in iron incorporation into RBC. In our patient, we think there must have been a reservoir of endogenous EPO production (possibly cystic kidneys), which was being modulated by chelation therapy with its likely effect on prolyl hydroxylases. 


\section{Disclosures}

None.

\section{Conflicts of Interest}

None.

\section{Funding}

None.

\section{References}

[1] El-Reshaid, K., et al. (1994) Erythropoietin Treatment in Haemodialysis Patients with Iron Overload. Acta Haematologica, 91, 130-135. http://dx.doi.org/10.1159/000204318

[2] Malcovati, L., et al. (2005) Prognostic Factors and Life Expectancy in Myelodysplastic Syndromes Classified According to WHO Criteria: A Basis for Clinical Decision Making. Journal of Clinical Oncology, 23, 7594-7603. http://dx.doi.org/10.1200/JCO.2005.01.7038

[3] Jabbour, E., et al. (2008) Red Blood Cell Transfusions and Iron Overload in the Treatment of Patients with Myelodysplastic Syndromes. Cancer, 112, 1089-1095. http://dx.doi.org/10.1002/cncr.23280

[4] Alessandrino, E.P., et al. (2010) Prognostic Impact of Pre-Transplantation Transfusion History and Secondary Iron Overload in Patients with Myelodysplastic Syndrome Undergoing Allogeneic Stem Cell Transplantation: A GITMO Study. Haematologica, 95, 476-484. http://dx.doi.org/10.3324/haematol.2009.011429

[5] Malcovati, L., et al. (2007) Time-Dependent Prognostic Scoring System for Predicting Survival and Leukemic Evolution in Myelodysplastic Syndromes. Journal of Clinical Oncology, 25, 3503-3510. http://dx.doi.org/10.1200/JCO.2006.08.5696

[6] Badawi, M.A., et al. (2010) Red Blood Cell Transfusion Independence Following the Initiation of Iron Chelation Therapy in Myelodysplastic Syndrome. Advances in Hematology, 2010, 164045.

[7] Jensen, P.D., Jensen, I.M. and Ellegaard, J. (1992) Desferrioxamine Treatment Reduces Blood Transfusion Requirements in Patients with Myelodysplastic Syndrome. British Journal of Haematology, 80, 121-124. http://dx.doi.org/10.1111/j.1365-2141.1992.tb06411.x

[8] Praga, M., et al. (1987) Improvement of Anaemia with Desferrioxamine in Haemodialysis Patients. Nephrology Dialysis Transplantation, 2, 243-247.

[9] Semenza, G.L. (1998) Hypoxia-Inducible Factor 1: Master Regulator of O2 Homeostasis. Current Opinion in Genetics \& Development, 8, 588-594. http://dx.doi.org/10.1016/S0959-437X(98)80016-6

[10] Wenger, R.H. (2000) Mammalian Oxygen Sensing, Signalling and Gene Regulation. The Journal of Experimental Biology, 203, 1253-1263.

[11] Wang, G.L. and Semenza, G.L. (1993) Desferrioxamine Induces Erythropoietin Gene Expression and Hypoxia-Inducible Factor 1 DNA-Binding Activity: Implications for Models of Hypoxia Signal Transduction. Blood, 82, 3610-3615.

[12] Schmid, M. (2009) Iron Chelation Therapy in MDS: What Have We Learnt Recently? Blood Reviews, 23, S21-S25. http://dx.doi.org/10.1016/S0268-960X(09)70006-2

[13] Prus, E. and Fibach, E. (2008) Flow Cytometry Measurement of the Labile Iron Pool in Human Hematopoietic Cells. Cytometry Part A, 73, 22-27. http://dx.doi.org/10.1002/cyto.a.20491

[14] Vreugdenhil, G., et al. (1993) Iron Chelators May Enhance Erythropoiesis by Increasing Iron Delivery to Haematopoietic Tissue and Erythropoietin Response in Iron-Loading Anaemia. Acta Haematologica, 89, 57-60. http://dx.doi.org/10.1159/000204488

[15] Aucella, F., et al. (1999) Synergistic Effect of Desferrioxamine and Recombinant Erythropoietin on Erythroid Precursor Proliferation in Chronic Renal Failure. Nephrology Dialysis Transplantation, 14, 1171-1175. http://dx.doi.org/10.1093/ndt/14.5.1171

[16] Ghoti, H., et al. (2010) Changes in Parameters of Oxidative Stress and Free Iron Biomarkers during Treatment with Deferasirox in Iron-Overloaded Patients with Myelodysplastic Syndromes. Haematologica, 95, 1433-1434. http://dx.doi.org/10.3324/haematol.2010.024992 
Scientific Research Publishing (SCIRP) is one of the largest Open Access journal publishers. It is currently publishing more than 200 open access, online, peer-reviewed journals covering a wide range of academic disciplines. SCIRP serves the worldwide academic communities and contributes to the progress and application of science with its publication.

Other selected journals from SCIRP are listed as below. Submit your manuscript to us via either submit@scirp.org or Online Submission Portal.
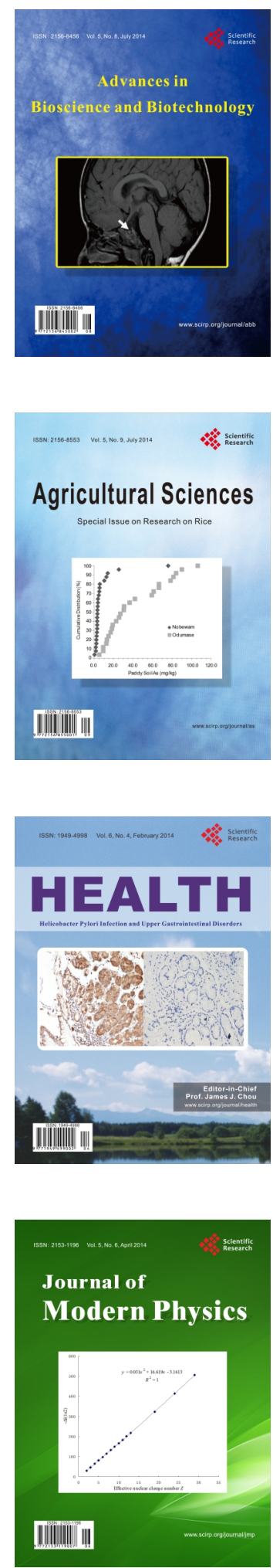
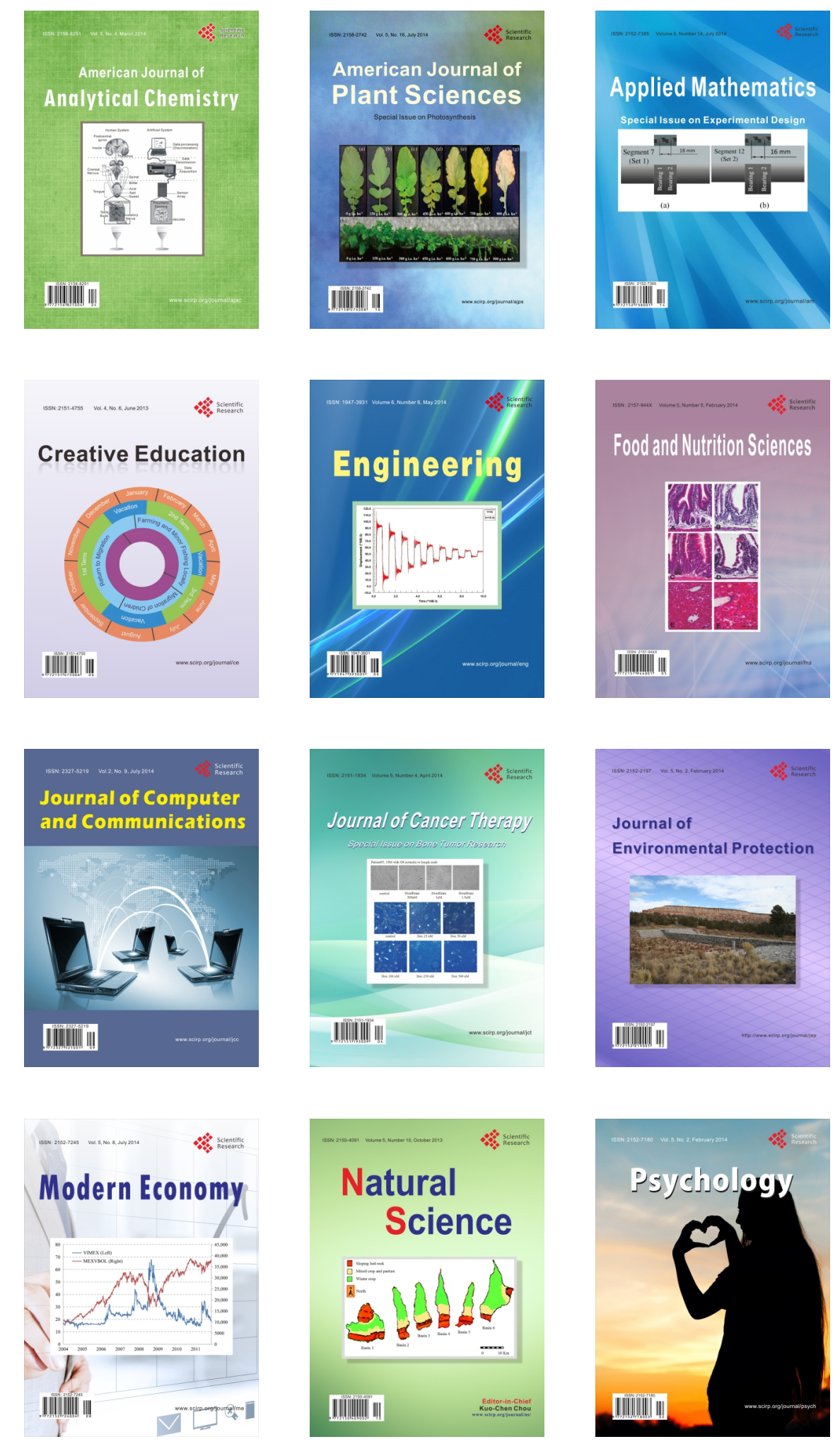